\title{
Studies on Chronic Cor Pulmonale with Special Reference to Coronary Circulation
}

\author{
Kiyoshi Hosono, M.D.*
}

\begin{abstract}
CCORDING to the report of an Expert Committee of World Health A Organization in $1961,{ }^{11}$ chronic cor pulmonale is defined as hypertrophy of the right ventricle resulting from diseases affecting the function and/or the structure of the lung, except when these pulmonary alternations are the result of diseases that primarily affect the left side of the heart or of congenital heart disease. Therefore, increase in pulmonary vascular resistance and pulmonary arterial hypertension arising from the structural change or dysfunction of the lung are naturally considered to play the most important role in the developement of cor pulmonale. However, little is known about the status of the left ventricle in cor pulmonale.

The author performed the following experiments in order to study the coronary circulation and the left ventricular function in chronic cor pulmonale.
\end{abstract}

\section{Material and Method}

The patients with chronic pulmonary diseases were employed in this study, including the cases of cor pulmonale. Coronary and pulmonary circulation were examined simultaneously by performing coronary sinus and right cardic catheterization. Coronary blood flow was measured by $\mathrm{N}_{2} \mathrm{O}$ method."2 Calculation of left ventricular residual volume was made as follows. Dye concentration curve was obtained by injecting T-1824 (Evans blue) dye or Coomassie blue dye into pulmonary artery or left auricle (when transseptal catheterization was performed) and sampling it from brachial artery. Left ventricular residual blood volume was calculated from the dye concentration curve according to the following formula (Table I).

\section{Results}

(1) Data on pulmonary and coronary circulation

The patients were divided into 2 groups. Group I consisted of the cases with the mean pulmonary arterial pressure $15 \mathrm{~mm} . \mathrm{Hg}$ or less. Group II consisted of the cases with the mean pulmonary arterial pressure $16 \mathrm{~mm} . \mathrm{Hg}$ or more, including the cases of cor pulmonale. One case in Group II was in congestive heart failure at the time of examination.

Lecturer, Department of Internal Medicine (Prof. Hirosi Sasamoto), School of Medicine, Keio University, Tokyo. 


$$
\begin{aligned}
& \text { Table I } \\
& V_{D}=V_{R}+V_{E} \\
& n=R t \\
& C_{2}=C_{1}\left(\frac{V_{R}}{V_{D}}\right)^{n} \\
& C_{2}=C_{1}\left(\frac{V_{R}}{V_{R}+V_{E}}\right)^{R t} \\
& \ln C_{2}-\ln C_{1}=R t \ln \left(\frac{V_{R}}{V_{R}+V_{E}}\right) \\
& \lambda=\frac{\ln C_{2}-\ln C_{1}}{t} \\
& \lambda=R ! \ln \left(\frac{V_{R}}{V_{R}+V_{R}}\right)
\end{aligned}
$$

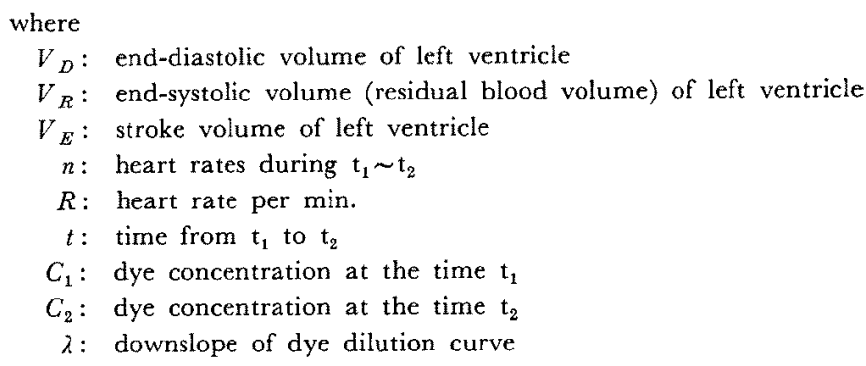

Data on pulmonary circulation are shown in Fig. 1.

Mean pulmonary arterial pressure was markedly elevated in the cases of cor pulmonale. The elevation of right ventricular end-disatolic pressure or pulmonary capillary pressure was found in some cases of Group II. These two pressures were markedly elevated in the cases with congestive heart failure: (shown with arrow in the Fig.). The decrease in arterial $\mathrm{O}_{2}$ saturation and the
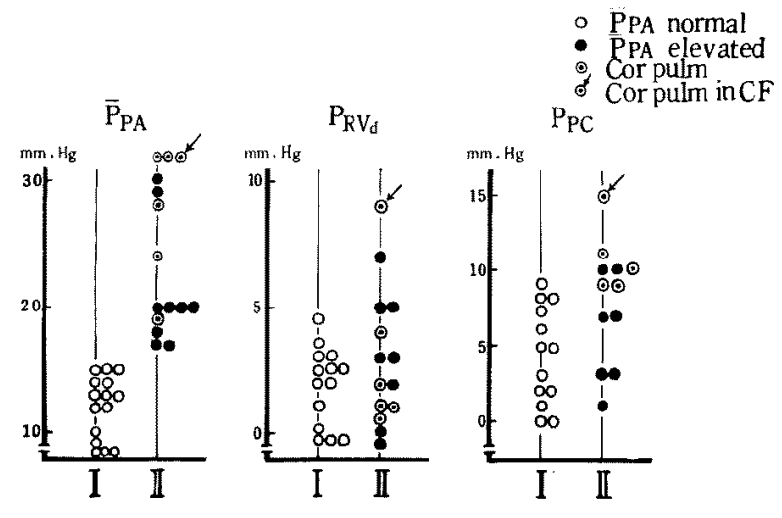

Fig. 1. Pulmonary circulation. 

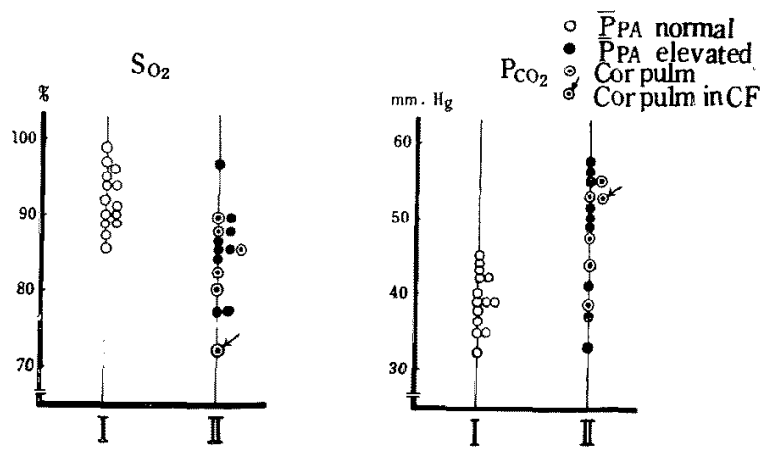

Fig. 2. Arterial blood gases.

increase in arterial $\mathrm{CO}_{2}$ tension were seen only in Group II, especially in the cases of cor pulmonale, as shown in Fig. 2.

(2) Data on coronary circulation

Any significant difference was not found between 2 groups in coronary blood flow, ratio of coronary blood flow to cardiac output, myocardial $\mathrm{O}_{2}$ consumption and coronary arterio-venous $\mathrm{O}_{2}$ difference $\left(\Delta \mathrm{O}_{2}\right)$. Myocardial $\mathrm{O}_{2}$ extraction coefficient increased in many cases of Group II, especially in most cases of cor pulmonale.

Coronary venous $\mathrm{O}_{2}$ tension decreased also in many cases of Group II, especially in most cases of cor pulmonale (Fig. 3 and Fig. 4).

Fig. 5 represents the relation between coronary arterio-venous $\mathrm{O}_{2}$ differcnce and coronary arterial $\mathrm{O}_{2}$ content.

Many cases of Group II, especially the most cases with cor pulmonale, belonged to the cases with relatively increased coronary arterio-venous $\mathrm{O}_{2}$ difference in relation to coronary arterial $\mathrm{O}_{2}$ content, namely the cases plotted

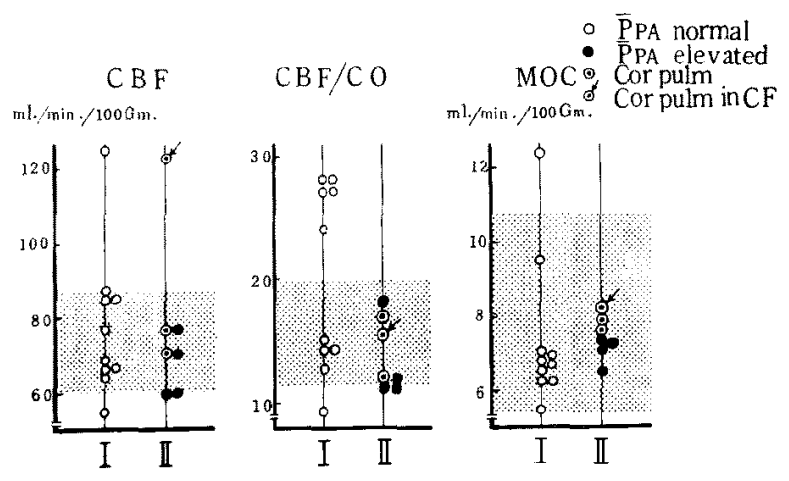

Fig. 3. Coronary circulation. 


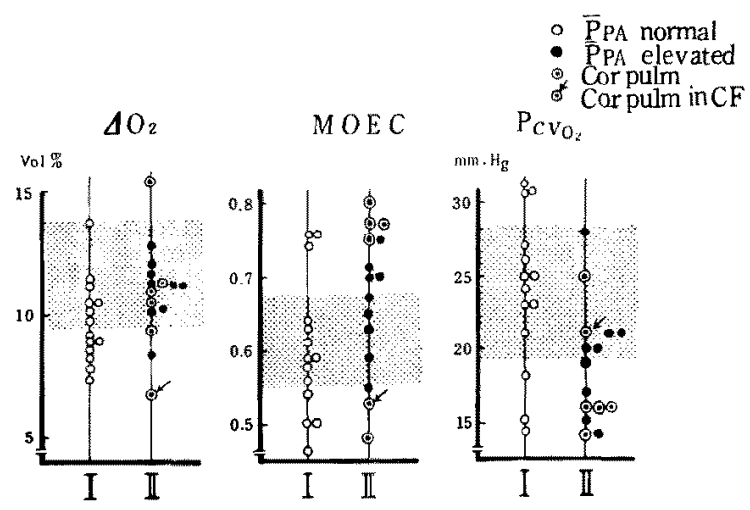

Fig. 4. Coronary circulation.

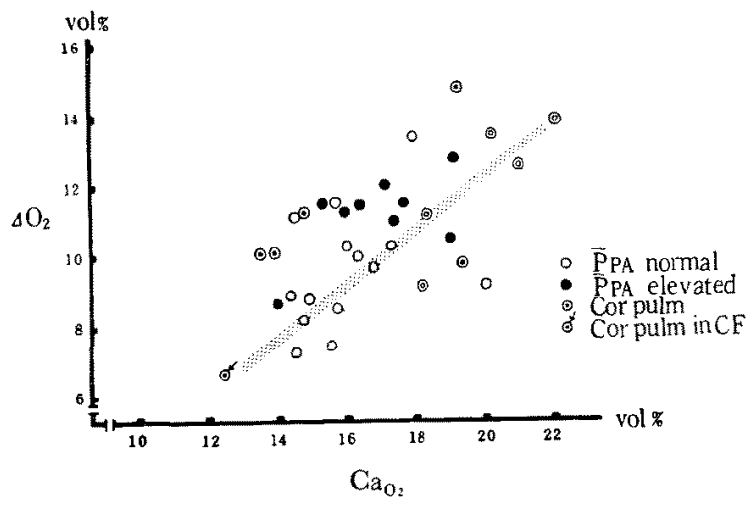

Fig. 5. Arterial $\mathrm{O}_{2}$ content and coronary arterio-venous $\mathrm{O}_{2}$ difference.

above the oblique line in Fig. 5. In other words, coronary arterio-venous $\mathrm{O}_{2}$ difference as against the same level of the arterial $\mathrm{O}_{2}$ content was greater in Group II, especially in cases of cor pulmonale, than in Group I.

The responses to the exercise test in normal subject and a patient in congestive heart failure with cor pulmonale are shown in Fig. 6. In normal subject, mean pulmonary arterial pressure and arterial $\mathrm{O}_{2}$ saturation did not change on exercise.

Coronary blood flow and myocardial $\mathrm{O}_{2}$ consumption increased, and coronary venous $\mathrm{O}_{2}$ tension was almost unchanged. "Excess lactate" and "redox potential" of myocardium were also unchanged. However, in the patient with cor pulmonale, mean pulmonary arterial pressure, already high at rest, rose further and arterial $\mathrm{O}_{2}$ saturation decreased on exercise. Cardiac output increased, but coronary blood flow and myocardial $\mathrm{O}_{2}$ consumption decreased. Coronary venous $\mathrm{O}_{z}$ tension also decreased markedly. 


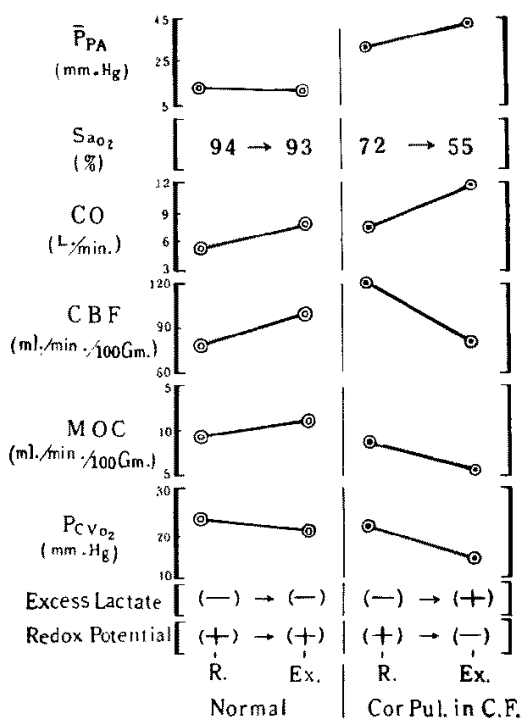

Fig. 6. Exercise test.

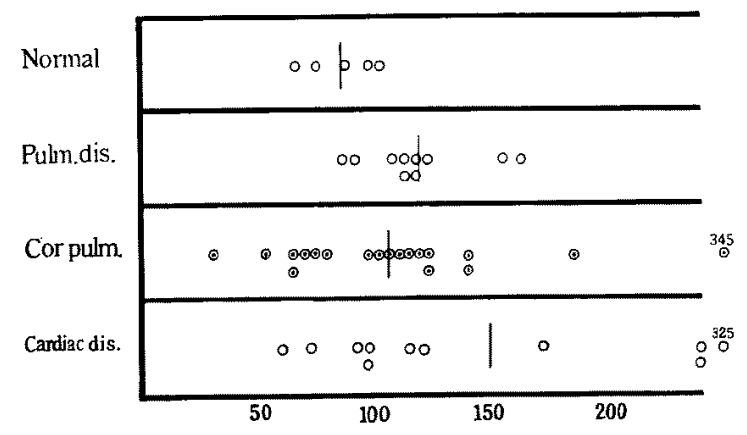

Fib. 7. Left ventricular residual blood volume.

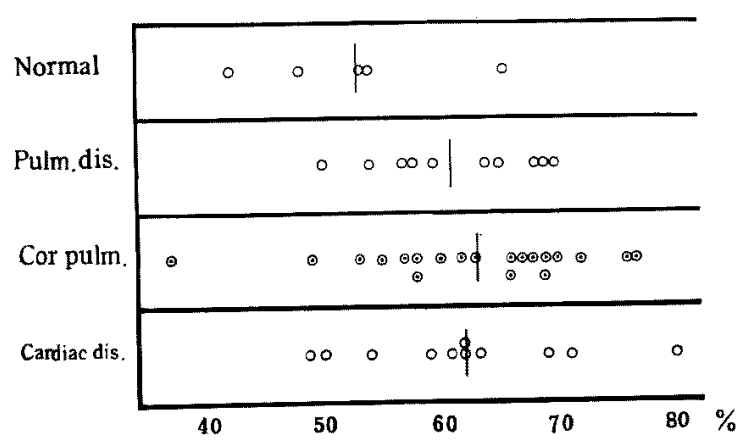

Fig. 8. Left ventricular residual ratio (RV/EDV). 
"Excess lactate" changed from negative to positive and "redox potential "from positive to negative.

(3) Data on left ventricular residual blood volume

The left ventricular residual blood volume tended to increase in the patients with chronic pulmonary disease, cor pulmonale and coronary sclerosis as compared with that in normal subject.

Left ventricular residual ratio, the ratio of left ventricular residual blood volume to end-diastolic volume, also increased in these patients as compared with that in normal subject (Fig. 7 and Fig. 8).

\section{Discussion}

Coronary venous $\mathrm{O}_{2}$ tension and myocardial $\mathrm{O}_{2}$ extraction coefficient are generally considered to reflect the $\mathrm{O}_{2}$ level of the left ventricular myocardium as a whole. And decrease in the coronary venous $\mathrm{O}_{2}$ tension and increase in myocardial $\mathrm{O}_{2}$ extraction coefficient are considered to indicate myocardial hypoxia in the left ventricle. "Excess lactate" and " redox potential " are also considered to be dependent on the $\mathrm{O}_{2}$ level of the myocardium. Positive "excess lactate" and negative "redox potential" are considered to reflect localized myocardial hypoxia.

On pulmonary circulation, hypoxemia and hypercapnia are found in the cases of pulmonary hypertension, especially markedly in the cases of cor pulmonale.

On coronary circulation, decrease in coronary venous $\mathrm{O}_{2}$ tension and increase in myocardial $\mathrm{O}_{2}$ extraction coefficient, which would indicate $\mathrm{O}_{2}$ lack in left ventricular myocardium, are found in the most cases of cor pulmonale. However, arterial $\mathrm{O}_{2}$ saturation also decreased in the cases of cor pulmonale. It is possible that decrease in coronary venous $\mathrm{O}_{2}$ tension in the cases of cor pulmonale is only due to decrease in coronary arterial $\mathrm{O}_{2}$ content and does not necessarily indicate myocardial hypoxia in the left ventricle.

Therefore, the relation between coronary arterial $\mathrm{O}_{2}$ content and coronary arterio-venous $\mathrm{O}_{2}$ difference was examined. As shown in Fig. 5, coronary arterio-venous $\mathrm{O}_{2}$ difference as against the same level of the coronary arterial $\mathrm{O}_{2}$ content tended to be greater in the cases with pulmonary hypcrtcnsion, especially in the most cases of cor pulmonale, than in the cases without pulmonary hypertension. Consequently, decrease in coronary venous $\mathrm{O}_{2}$ tension in the cases of cor pulmonale cannot be attributed only to decrease in coronary arterial $\mathrm{O}_{2}$ content, but it indicates the existence of myocardial hypoxia in the left ventricle.

In the patient with cor pulmonale and congestive heart failure, coronary 
blood flow did not increase and coronary venous $\mathrm{O}_{2}$ tension decreased markedly on exercise. "Excess lactate" and "redox potential" became positive and negative, respectively. These results strongly suggest that myocardial hypoxia in the left ventricle was developed because of the disturbance of coronary circulation during exercise. Left ventricular residual blood volume and left ventricular residual ratio were generally greater in the cases with chronic pulmonary disease than in normal subjects, which was marked in the cases of cor pulmonale. From the foregoing results, it seems justified to say that the cases of cor pulmonale are in the latent phase of left heart failure.

\section{Summary}

(1) Myocardial hypoxia in the left ventricle exists at rest in the most cases of cor pulmonale, which is not due to decrease in arterial $\mathrm{O}_{2}$ saturation.

(2) In some cases of cor pulmonale, myocardial hypoxia in the left ventricle develop because of the disturbance of coronary circulation during exercise.

(3) Residual blood volume and residual ratio of left ventricle tended to increase in cases of cor pulmonale.

(4) From the foregoing facts, it can be said that the case of cor pulmonale is in the latent phase of left heart failure.

\section{References}

1. World Health Organization Technical Report Series No. 213.

2. Kety, S. S. and Schmidt, C. F.: Am. J. Physiol, 143: 53, 1945. 